\title{
Burden of cancer pain in developing countries: a narrative literature review
}

This article was published in the following Dove Press journal:

ClinicoEconomics and Outcomes Research

\section{Zhang Li' \\ Tiara Aninditha ${ }^{2}$ \\ Brahim Griene 3 \\ Javier Francis ${ }^{4}$ \\ Paulo Renato 5 \\ Alain Serrie ${ }^{6}$ \\ Indira Umareddy ${ }^{7}$ \\ Sebastien Boisseau ${ }^{8}$ \\ Yacine Hadjiat ${ }^{8}$ \\ 'Sun Yat-Sen University Cancer \\ Center, Guangzhou, Guangdong, \\ China; ${ }^{2}$ Mangunkusumo Hospital, Jakarta, Indonesia; ${ }^{3}$ Pierre and Marie Curie Centre, Algerie, Algeria; ${ }^{4} \mathrm{St}$. Luke's Medical Center, Quezon City, Philippines; ${ }^{5}$ Anesthesiology Service and Clinical Oncological IOC Group Pain, Brazil; ${ }^{6}$ Hospital Lariboisiere, Paris, France; ${ }^{7}$ Kantar Health, Singapore, Singapore; ${ }^{8}$ Mundipharma Pte Ltd., Singapore, Singapore}

Correspondence: Yacine Hadjiat Mundipharma Pte Ltd, 12 Marina View, \# 22-0I Asia Square Tower 2, Singapore 01896I, Singapore Email yacine.hadjiat@mundipharma.com.sg

\begin{abstract}
Cancer pain is one of the most common, feared, debilitating, and often undertreated symptoms among cancer patients. It needs attention since it has a significant impact on the quality of life (QoL) of the patients. Also, since cancer has emerged as a major health problem in developing countries, there is a need to strengthen preventive strategies for effective cancer pain management and provide comfort to cancer patients. Nonetheless, various barriers limit developing countries toward optimal cancer pain management. To bridge the gap between adequate pain management and burden of cancer pain in developing countries, a comprehensive understanding of the limitations faced and the prevalence of cancer pain should be addressed. The aim of this literature review is to provide a deeper understanding on the factors associated with cancer pain as well as barriers toward optimal cancer pain management in developing countries. Some of the barriers addressed were administrative, judicial, economic, and professional barriers. Also, estimates on the prevalence of cancer pain and detrimental effects of pain on the QoL of cancer patients have been addressed. In summary, pain, which is one of the most debilitating symptoms of cancer, remains uncontrolled and undertreated in developing countries. It has a profound impact on the patient's QoL and can have physical, psychological, and social consequences; therefore, it needs to be managed urgently and appropriately. Most importantly, optimal treatment of cancer pain should be highlighted as a priority in developing countries and concerted efforts should be made to eliminate different barriers discussed in this review for effective and humane care.
\end{abstract}

Keywords: cancer, pain, health care, economic, quality of life, developing countries

\section{Background}

The prevalence of noncommunicable diseases (NCDs) generally, and cancer specifically, has increased globally and particularly so in developing countries. ${ }^{1}$ Low- and middle-income countries constitute almost $85 \%$ of the world's population and contribute significantly to the global burden of cancer. ${ }^{2}$ Asia, Africa, and Latin America are collectively home to more than $50 \%$ of cancer patients $;{ }^{3}$ with more than half of global cancer-related mortalities occurring in Asia alone. ${ }^{3}$ Cancer is a multisymptomatic health condition with physical, psychological, social, spiritual, and emotional sequelae. ${ }^{4}$ Pain is one of the most common, debilitating, and feared symptoms of cancer. ${ }^{4-9}$ It is a complex phenomenon comprosed of sensory, affective, cognitive, and behavioral components. ${ }^{10}$ Cancer pain is prevalent in almost $50 \%$ of all cancer patients ${ }^{4,7,8}$ and more than $70 \%$ of patients with advanced cancer. ${ }^{4,8}$ About half of patients suffer with advanced cancer experience moderate-to-severe pain, while almost a quarter of patients 
suffer with more severe pain. ${ }^{7,9,11}$ Pain is also associated with cancer treatment with more than $25 \%$ of patients enduring moderate-to-severe pain during treatment. ${ }^{7,9,11}$

The WHO recommends a three-level ladder approach to pain management, which includes the use of opioids. ${ }^{12}$ This approach has been widely adopted and has led to satisfactory relief in the significant proportion of patients. ${ }^{13}$ However, despite the existence of clinically proven guidelines, the prevalence of undertreated cancer pain is relatively high in Asia, ie, 59\% compared with $40 \%$ in Europe and $39 \%$ in USA. $^{14}$

Untreated or inadequately treated pain can have a severe negative impact on the physical and psychological health, ${ }^{6,15}$ functional status, and quality of life $(\mathrm{QoL})^{6,10}$ of cancer patients. Pain negatively impacts daily activity, mobility, functioning, sleep quality, entertainment, social interaction, and the professional life of cancer patients. ${ }^{6,7,16,17}$ The duration and intensity of pain affect QoL, ${ }^{15,18-20}$ and in turn, poor QoL exacerbates the severity of the pain. ${ }^{6}$ At its worst, severe pain may also lead to an unwillingness to take medications and a desire for death. ${ }^{21}$

Thus, suboptimal pain control can also be very debilitating and, despite the international guidelines for pain relief by $\mathrm{WHO}^{22}$ it still remains inadequately treated ${ }^{23-25}$ with advances toward cancer pain relief limited to developed nations. ${ }^{26,27}$ Low- and middle-income countries have a number of barriers to effective pain management including legislative, regulatory, health care professional, and cultural barriers. ${ }^{10,30-33}$ Health care and opioid therapy are not easily accessible or available, ${ }^{32}$ and prescribers face challenges at various levels when handling opioids. ${ }^{31}$ Lack of awareness among patients and caregivers and lack of training of health care professionals further exacerbate the situation, ${ }^{29-31}$ leading to an increasingly negative impact on patient's QoL. Therefore, there is a higher prevalence of cancer pain in Asia (27-79\%) compared to North America and Europe $(39.1-40.3 \%) .^{24}$

Moreover, undertreatment or undermanagement of cancer-related pain results in higher indirect cost burden (transportation and health care resource utilization) because of larger number of patients or even cancer survivors, who require several unnecessary hospital admissions, visits to the emergency departments, or worst-case scenario long-term psychosocial treatment. ${ }^{32-34} \mathrm{Up}$ to $76 \%$ of cancer patients experience pain that requires significant direct and indirect resource utilizations. ${ }^{35}$ This review provides insights into various aspects of burden developing countries face while managing pain in cancer patients. Overall, this review might help to increase awareness among regulators, patients, physicians, and caregivers regarding the inadequacy of pain management in developing countries and highlight various contributing factors as well as barriers to treatment access.

\section{Methodology}

It is a study of narrative review of the literature. The literature review was conducted to estimate the clinical, humanistic, and economic burdens of cancer pain in developing countries in Asia, Latin America, Africa, and the Middle East. PubMed, Cochrane, the NHS Economic Evaluation Database (NHS EED), and the cost effective analysis (CEA) registry were searched for empirical and peer-reviewed literature. Conference abstracts, RePEc, EconLit, OAIster, websites of government ministries, cancer registries, palliative or hospice care societies, and local organizations among others were searched for gray literature. Nonsystematic searches were also performed on Google and Google Scholar (Table S1). The search strategy was constructed using combinations of various key terms for pain, cancer, epidemiology, direct and indirect costs, developed countries, Asia, Africa, Latin America, and health-related QoL (HRQoL). The search terms were used to find information on the comparative view of pain management among developed and developing countries as well as understand the factors contributing to pain management in both settings. No terms for the type of studies were included in search strings to keep the strategies more sensitive. A total of 3,488 unique articles were initially identified. Following the application of screening and eligibility criteria (Table S2), in the end, there were 352 combinations to obtain maximum references possible. Search parameters included English language, full-text studies, conducted in Asia, Africa, Latin America, or the Middle East, among adult cancer patients and published during December 2011 to December 2016 (Table S2 for inclusion criteria). Study types ineligible as per the inclusion criteria were excluded during screening phase. Cost-effectiveness, cost-benefit, cost-minimization, and budget impact studies were not included (Table S2 for exclusion criteria).

\section{Results}

The incidence and prevalence of cancer are growing in the developing world and are adding to the substantial economic burden of NCDs

NCDs are the leading cause of death worldwide. According to WHO's global status report on NCDs, 38 million deaths 
occurred due to NCDs in $2012,75 \%$ of which occurred in low- and middle-income countries. ${ }^{36}$ The estimated number of deaths due to NCDs is predicted to rise to 55 million by $2030 .{ }^{37}$ In 2012, cancer was the second leading cause of NCD-related death accounting for an estimated 8.2 million (21.7\%) deaths. ${ }^{36}$ As per the 2014 world cancer report, Asia constitutes approximately half of the global burden of cancer. China and India collectively contribute to about a quarter of global cancer incidence similar to that found in Europe. The proportion of cancer mortality shows a gradual increase in the Asia and Africa regions, in contrast to a gradual decrease in the regions of Europe and North America. The most common cancers diagnosed in men were lung $(16.7 \%)$ and prostate (15\%), while the most common cancers diagnosed in women were breast $(25.2 \%)$ and colorectal $(9.2 \%){ }^{38}$

The growing burden of cancer incidence and prevalence results in an overall increase in economic burden. ${ }^{39} \mathrm{~A}$ study published in 2011 described the substantially and gradually increasing economic burden of cancer in USA. This financial burden may result in failure to complete treatment in insured and uninsured patients and affect the employment status of both patients and caregivers. ${ }^{39}$ The US National Health Interview Survey (2004-2014) reported a substantial economic burden among adult survivors of childhood cancers. This study indicated an annual productivity loss of USD 8,169 per person in survivors of childhood cancer as compared to USD 3,083 per person for individuals without a history of cancer. ${ }^{40}$

Studies in developing countries show an even more dire economic impact. A study conducted on lung cancer survivors in China suggested that the economic burden of cancer accounted for $171 \%$ of household annual income, which reduced to only $107 \%$ on receiving compensation from health insurance. ${ }^{41}$ A study conducted in Korea reported an $8.9 \%$ annual growth rate in the economic burden of cancer. ${ }^{42}$ In India, the National Sample Survey Organization (NSSO) reported high out-of-pocket health expenditures in households with cancer compared to controls, ranging from INR 3,576 to INR 4,438 per member annually. ${ }^{43}$

\section{Cancer creates a significant humanistic burden}

Cancer and its treatments such as radiotherapy and chemotherapy have negative consequences on physiological and psychological functioning as well as social and family interactions. Together these lead to the deterioration of patient's QoL. ${ }^{44}$ Type of cancer, pain intensity, and fatigue are the primary factors that modulate QoL in cancer patients. ${ }^{45}$ Although a pre- and postcancer diagnosis study conducted in elderly Americans reported a debilitating effect on HRQoL irrespective of the cancer site; certain cancers such as nonsmall-cell lung cancer have been found to have a greater negative impact on physical and mental health functioning. ${ }^{46}$ Impact of cancer is felt beyond the patients, with caregivers also experiencing negative consequences. This impact of cancer on caregivers is seen in both developed and developing countries. A study showed that caregivers in Asia had a relatively lower QoL compared to its western counterparts (UK, USA, and Canada). ${ }^{47}$ Another study in Africa also demonstrated high level of caregiver burden, psychological morbidity, and financial strains. ${ }^{48}$ Thus, cancer creates a significant burden on the QoL of not only patients but also caregivers with few studies suggesting higher impact on the QoL of caregivers in Asia compared to developed countries.

\section{Pain is one of the most common symptoms of cancer}

A meta-analysis published in 2007 concluded that there has been no improvement in the treatment of cancer pain around the globe over a period of 40 years. This study reported a 59\% prevalence of cancer pain in patients on anticancer treatment, a $64 \%$ prevalence in patients with advanced/metastatic/terminal disease, and a $53 \%$ prevalence in patients at all disease stages. ${ }^{49}$ Despite increased attention to pain management in cancer patients, similar results were found in the updated version of this review, which summarizes pain prevalence over a period of 9 years. ${ }^{50}$

In this literature review, 10 studies described the prevalence of cancer pain. Three studies were conducted in Asia (Taiwan, China, and Korea), ${ }^{20,51,52}$ three studies were conducted in the Middle East (Lebanon, Jordan, and Yemen), ${ }^{31,53,54}$ two studies were conducted in Africa (Republic of South Africa and Uganda), ${ }^{55,56}$ and two studies were conducted in Latin America (Brazil). ${ }^{57,58}$ The prevalence of cancer pain in all 10 studies ranged from 31.9 to $87.5 \%$. The median prevalence was found to be $51.9 \%$ in Asia, $70.0 \%$ in the Middle East, $61.6 \%$ in Africa, and $42.1 \%$ in Latin America (Table 1).

\section{Factors associated with cancer pain}

Certain factors such as psychosocial and socio-economical have been associated with cancer-related pain in low- and middle-income countries with inadequate assessment and management of cancer pain..$^{59,60}$ Limited studies so far have reported a clear understanding of psychosocial factors associated with cancer pain, especially in relation to aging with some studies reporting no relationship with age ${ }^{61-63}$ and oth- 


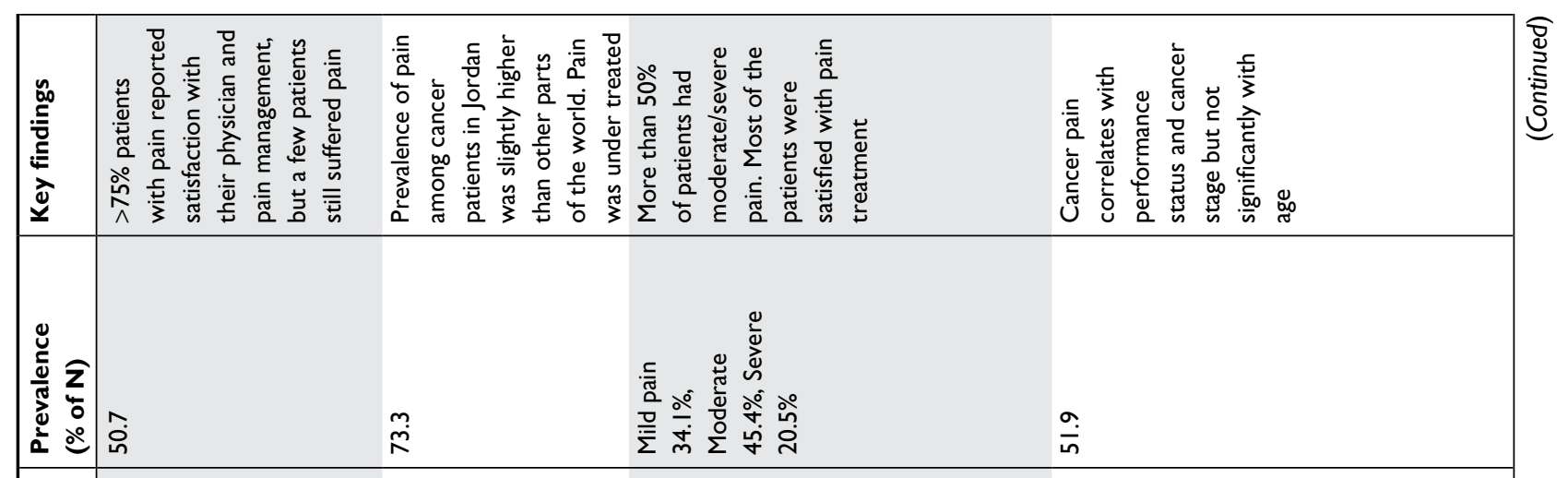

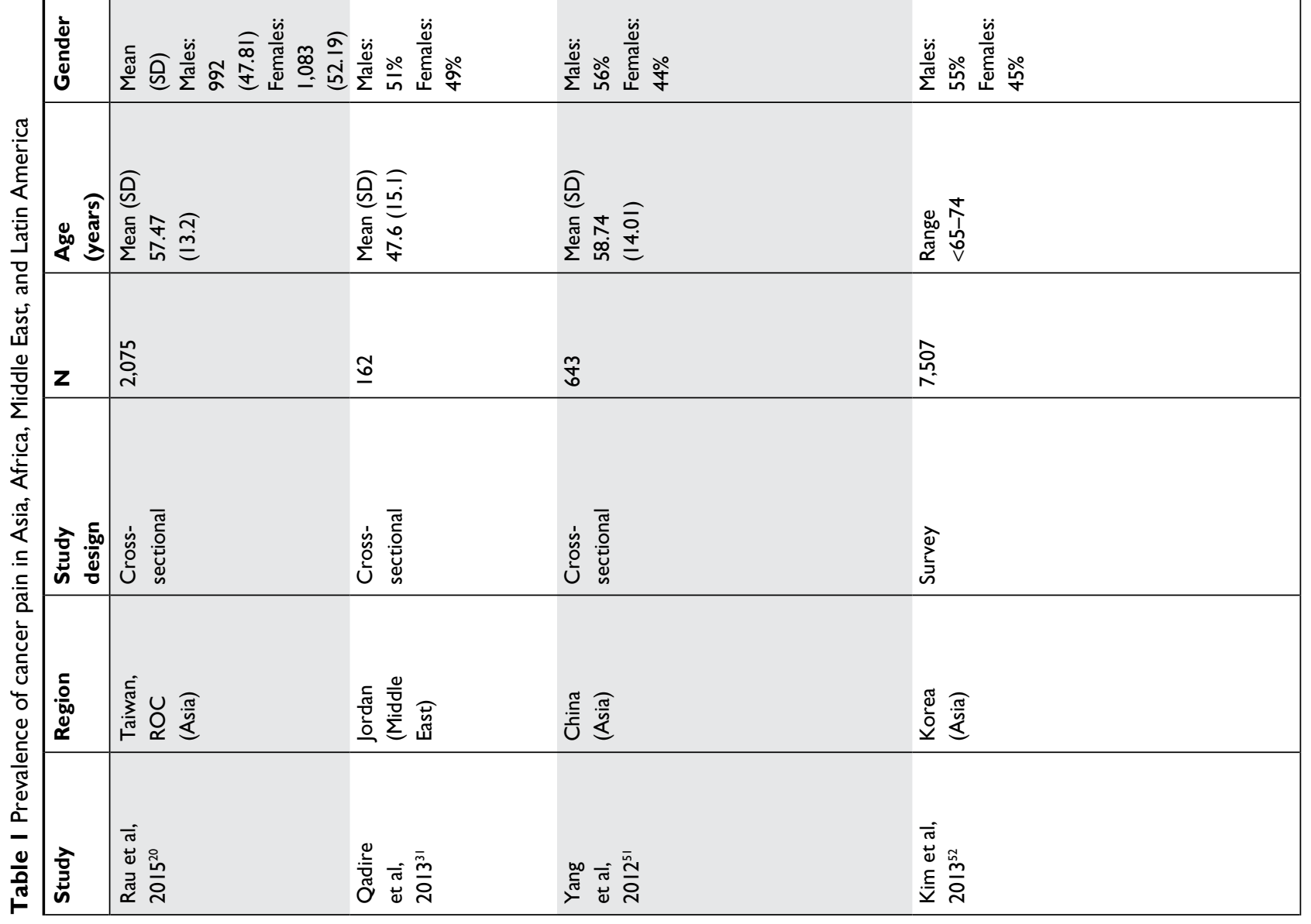




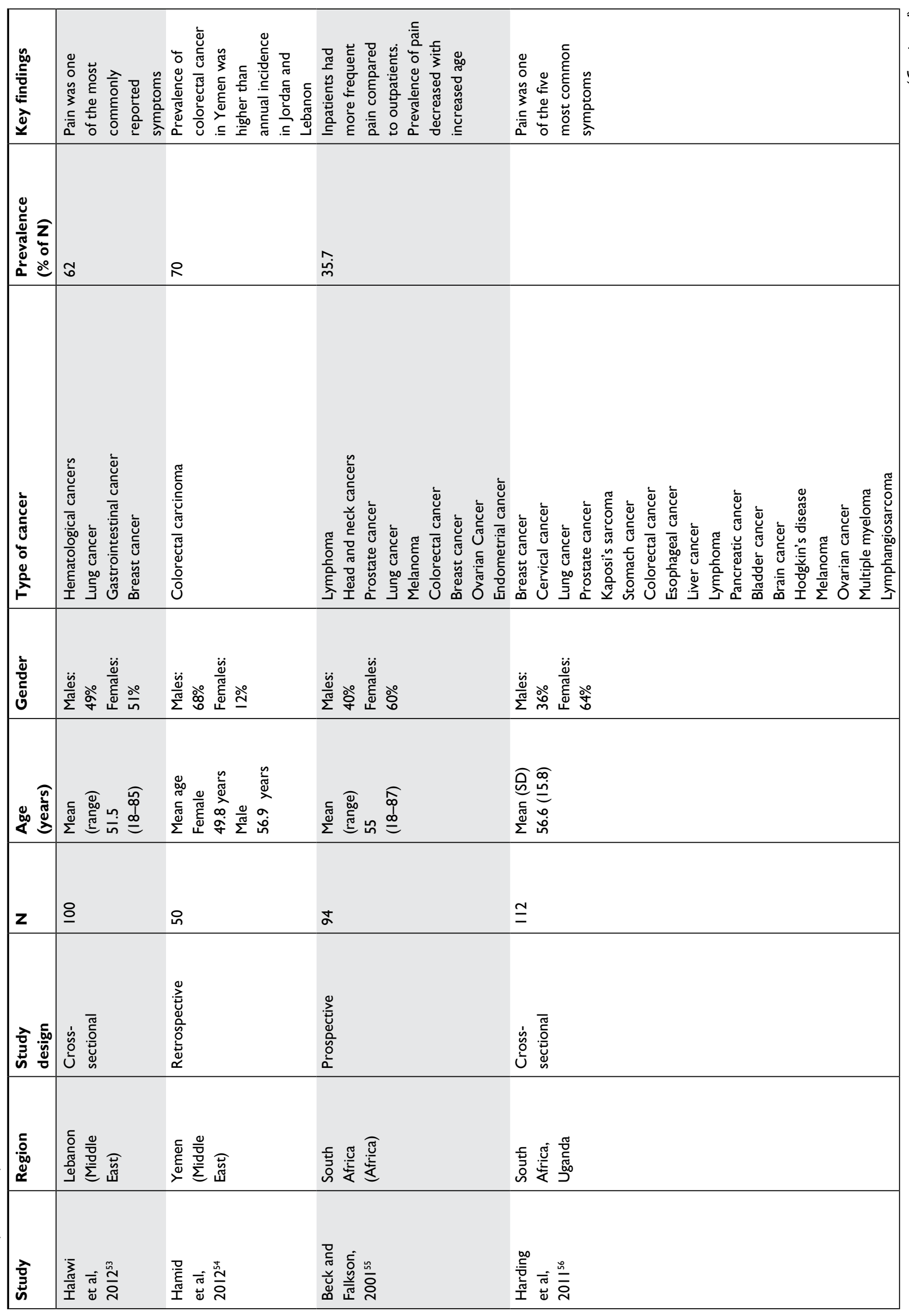




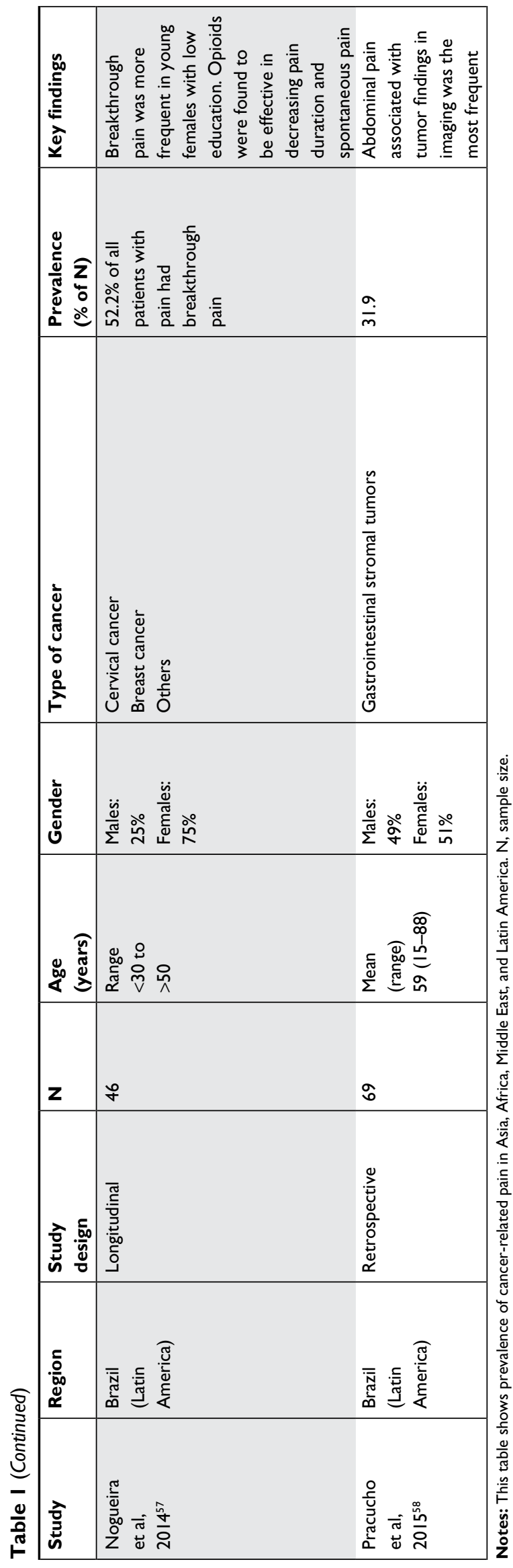

ers reporting interference with age. For example, a study in 2012 demonstrated that advancing age results in an increased prevalence of cancer pain. This study found a $50.0 \%$ prevalence of pain in cancer patients aged less than 65 years, a $55.9 \%$ prevalence of pain in those aged $65-75$ years, and a $58.3 \%$ prevalence of pain in those older than 75 years. However, no difference in risk of cancer pain was observed in patients with the same performance status classified under different age groups. ${ }^{52}$ Another study identified young age (18-39 years) as one of the factors associated with chronic pain after surgical treatment of breast cancer. ${ }^{64}$ Additionally, another study reported high prevalence of cancer pain in patients belonging to the 29-39 years age group..$^{10}$ Thus, it is clear that a better comprehension of the age-related patterns association with cancer pain is necessary to address the variability across different studies.

While the association of age-related psychosocial factors with pain is more or less prevalent in both developed and lowmiddle income countries, socio-economic factors such as fear and misconceptions regarding addiction to opioids for palliative care, lack of preventive strategies, poverty, illiteracy, and social stigma over the use of morphine are some of the additional factors associated with an increased prevalence of cancer-related pain in low- and middle-income countries. ${ }^{59}$ For example, in India, despite WHO efforts on increasing awareness for analgesic use, little progress has been made in relieving pain in cancer patients (social stigma).$^{65}$ In another example in Nigeria, hospitals outside the commercial city of Lagos do not have morphine available and need additional expenses (travel costs) to make morphine accessible to smaller cities/areas; thus, lack of infrastructure and poverty attributes toward cancer-related pain since most of the small hospitals are unable to afford these additional expenses. ${ }^{66}$

Thus, socio-economic factors such as poor education of health professionals, limited facilities for pain treatment, misconception about pain drugs (addiction), fear of side effects, and poor access to drugs for pain relief especially in low- and middle-income countries often result in inappropriate pain management. There is a vast disparity between developed and developing countries on access to cancer pain relief. A report from the International Narcotics Control Board (INCB), 2015, showed that approximately $95 \%$ of the worldwide use of opioid analgesics is consumed in countries with only $15 \%$ of the world population (USA, Canada, countries in western Europe, Australia, and New Zealand), while $75 \%$ of the world population predominantly from the low- and middle-income countries is left with limited or no access to proper pain relief. ${ }^{67} \mathrm{Also}$, another study in Jordan 
showed that of the 122 patients studied for the adequacy of cancer pain management, $31 \%$ had not received treatment for pain. Most of the patients with pain (65\%) received either no treatment or insufficient treatment. ${ }^{68}$ Additionally, there are disparities between developed and developing countries on the physician's experiences and attitudes toward cancer pain management, which also contributes to inappropriate cancer pain management. A comparative study of physician's attitude toward cancer pain management between high- and low-income countries emphasized that lack of training and expertise and cultural values/beliefs were more prohibitive for physicians in low-income settings compared to those in high-income settings. ${ }^{69}$ Also, in Philippines, for example, although most of the physicians were aware of the WHO analgesic ladder for cancer pain management, there was resistance among the physicians to prescribe strong opioids such as morphine. Thus, barriers such as resistance from physicians to opioid use still exist in Philippines contributing to an inappropriate management of cancer pain..$^{70}$ Ergo, there are disparities in the level of cancer pain management between developed and developing countries, wherein there is a recognition of the vital role of medical use of opioid analgesics for moderate-to-severe pain relief for cancer patients in developed countries. In contrast, several factors contribute to inappropriate management of cancer pain in developing countries, which includes, but is not limited to, unavailability of opioid analgesics, unconquered barriers such as lack of formal training of doctors, cultural values/ beliefs, and reluctance of physicians to use opioid analgesics for cancer treatment.

With several barriers to opioid prescription, patients in low- and middle-income countries often receive other medications such as paracetamol for severe cancer pain management. ${ }^{71}$ A study in Cyprus showed that majority of cancer patients were prescribed paracetamol and nonsteroidal anti-inflammatory drugs (NSAIDs) with very low prescription behavior of strong opioids. ${ }^{72}$ Also, a study from Senegal showed inappropriate management of cancer pain due to the lack of availability of morphine. Physicians often prescribed paracetamol for the management of severe cancer pain in Senegal. ${ }^{73}$ Besides analgesics such as NSAIDs and paracetamol, cancer patients are also administered alternative treatment options in developing countries. For example, a study in China showed that though opioid was administered for cancer-related pain treatment, patients also received other treatment options such as Traditional Chinese Medicine (TCM), physical therapy ie, massage, hydrotherapy, and transdermal patches. ${ }^{74}$ In Mongolia, a significant propor- tion of patients restored to complementary and alternative medicines (CAMs) for managing cancer symptoms such as pain. Some of the CAM modalities included products of animal origin, herbal medicines, mind-body therapies, dietary supplements, and Mongolian traditional medicines. ${ }^{75}$

Another factor associated with cancer pain is apathy toward cancer pain management, where, often, there are insufficient knowledge and poor understanding regarding the use of analgesics for pain management. Patients often consider cancer pain as a normal condition of the disease. This inappropriate pain management is then negatively associated with patients' QoL. ${ }^{52}$ Treatment modalities have also shown to influence pain prevalence, for example, treatment with radiotherapy was found to be an underlying factor in the increased prevalence of pain. ${ }^{10}$ There has also been an association between cancer pain and repeated hospitalizations of cancer patients. A study reported recurrent moderateto-severe pain episodes during repeated hospitalizations, which the researchers interpreted as an inadequate approach to pain management. ${ }^{76}$ In contrast, another study reported a decreased prevalence of pain upon repeated hospitalizations, implying that appropriate management practices may reduce pain. ${ }^{77}$ Thus, further studies are warranted to clearly understand the variability across different studies. Finally, the method of pain assessment itself has been shown to influence prevalence rates, for example, a study revealed higher prevalence in patient-assessed pain than in physicianassessed pain. ${ }^{78}$

Thus, a multitude of factors associated with cancer-related pain needs to be addressed to improve pain management, especially in low- and middle-income countries. Given the multidimensional nature of cancer pain and undertreatment of this pain, there is a need to overcome numerous barriers toward effective pain management.

\section{Barriers to appropriate opioid treatment for cancer pain management and palliative care}

\section{Administrative and judicial barriers}

The most widespread barrier to the optimal management of pain is the judicial restrictions imposed by several governments to control the illicit use of narcotics, subsequent to the Single Convention on Narcotic Drugs of 1961 (INCB 1961), and amended by the 1972 protocol. ${ }^{79,80}$ Several governments have imposed stricter regulations than those required by the Single Convention in an attempt to curb the illicit use of opioids. These attempts generally result in patients being deprived of access to effective treatment for pain. ${ }^{79,80}$ In some 
countries, such as Morocco, the Philippines, and Egypt, special licenses for the prescription of opioids are mandatory and only certain doctors can prescribe opioids. ${ }^{79}$ Doctors seeking licenses may have to first obtain police clearance or take a urine test to clear any suspicions that they may personally abuse drugs or have a criminal record.

Several countries have imposed the requirement for a special prescription form that is also not mandated by the Single Convention. The WHO has stated that this special requirement reduces the prescription of controlled drugs by medical personnel's by more than half. ${ }^{81}$ In Morocco, doctors can obtain special prescription forms only after exclusive applications; in Philippines, doctors have to pay for prescription forms; and in Turkey, obtaining enough special forms is problematic. ${ }^{79}$ In China, only tertiary hospitals are allowed to dispense opioids, which make it difficult for patients residing in remote areas to access analgesics. ${ }^{30}$

Other examples of restrictions include a limit on the daily dose of morphine in Turkey, a limit on the dose of a single prescription in Egypt, and a limit on the monthly dose of morphine in the Philippines. Some countries also limit the maximum duration for a prescription. Cambodia, Egypt, and Morocco have a limit as short as 7 days, and Argentina and Jordon limit the duration to 10 days. China decides the limit based on the formulation of the morphine - 15 days for immediate release tablets, 7 days for slow release tablets, and 3 days for injectable morphine. ${ }^{82}$

These regulations make it difficult for doctors to prescribe opioids, they prevent patients from having access to optimal care, and they also dissuade health care professionals from using the appropriate treatment by restricting them with legal sanctions. Sometimes restrictive regulations, criminalization of even unintentional misconduct, and fear of legal actions such as harsh punishments and revocation of medical licenses discourage prescribers from using controlled drugs to treat pain. ${ }^{82}$ In addition, onerous paperwork and bureaucratic hurdles deter hospitals from stocking and dispensing opioids. ${ }^{29}$

\section{Professional barriers}

There are a number of barriers pertaining to health care professionals that lead to the inadequate management of cancer pain. Many health care professionals lack adequate education and training, have several misconceptions about pain and analgesics, and may be overburdened or too stressed to provide sufficient attention to pain management. ${ }^{29,30,68}$ Assessment is the first step for effective pain management; however, physicians often do not feel the need to conduct an assessment and lack the knowledge about how to assess the pain. ${ }^{83}$ Guidelines and assessment tools exist but are not implemented in clinical practice, instead physicians follow local clinical practices. ${ }^{30}$ Thus, there is a need to address suboptimal pain recognition, assessment, and treatment due to inadequate education of health care practitioners. A study from India showed that the basic knowledge about pain was deficient among young anaesthesiologists. ${ }^{84}$ In developed countries such as France, dedicated modules on pain management were included in the curriculum of medical students. ${ }^{85}$ Therefore, supporting education would further facilitate appropriate opioid use and adequate pain management.

Also, misconceptions about both cancer pain and its treatment were identified in a number of research studies. There is a misperception that pain is an inevitable consequence/ symptom of cancer and that it needs to be endured by patients, while clinicians focus on treating the cancer. One physician stated "Cancer means death with pain...no one can help... you (patient) have to tolerate it". Patients with pain were discharged and left on their own to manage the consequences. ${ }^{83}$

Furthermore, there is evidence that clinicians distrust patient's reports of pain while receiving cancer therapy as they believe that cancer treatments cannot cause pain and only relieve it. ${ }^{86}$ Caregivers also reported that clinicians do not trust or believe them when they advocated for patients enduring pain. ${ }^{83}$ A 2014 study in India investigated the barriers to cancer pain management and opioid availability, and the key barriers included the role of nursing, opioid misconceptions, bureaucratic hurdles, and sociocultural/infrastructure challenges. ${ }^{26}$ Macro- and microlevel policy and practice changes are needed to improve opioid availability and cancer pain management in India.

\section{Patient barriers}

Patients' attitudes and beliefs about pain medication can create an additional barrier to optimal pain management. Patients describe a fear of developing tolerance and addiction and are also concerned about the perceived harmful effects of opioids. ${ }^{87}$ The dosage of opioids is generally reduced due to concerns about drug addiction. ${ }^{6}$

Patients generally try to find solace and inspiration in their spiritual beliefs and community support. ${ }^{28}$ They believe that pain is inevitable and accept it as their fate; they consider pain normal and avoid using analgesics. ${ }^{10}$ Lee et al studied Asian (Singapore Chinese) patients with advanced cancer and found that pain has a complex combination of physical, mental, and existential elements. Patients believed that no one but they themselves had to bear the pain and preferred dying than letting others know that they were suffering. ${ }^{88}$ Gender 
roles also played a part in how pain was expressed - men were less likely to express their pain due to the social expectation for men to be strong. This leads to the undertreatment of pain in men, while women express their pain more effectively and are more prone to seek help. ${ }^{10}$

Families and caregivers advocate for patients ${ }^{29}$; however, they lack sufficient knowledge and depend largely upon clinicians for optimum pain management. ${ }^{83}$ Misconceptions among clinicians are transmitted to patients and contribute to their lack of knowledge as clinicians are seen as the most reliable source of information for patients. ${ }^{83}$

Affordability of treatment, especially among poorer patients, constitutes an additional barrier to the undertreatment of pain. Patients with lower economic status often do not seek medical support for cancer pain management. ${ }^{6}$ Families remain concerned about their heavy economic burden, which makes it difficult for the clinicians to prescribe/apply appropriate dosing. ${ }^{83}$ This high cost burden of illness on the family may result in guilt among patients and could lead to underreporting of the pain. Patients often tend to save opioids for only severe pain, and this results in them undertreating themselves. ${ }^{30}$ Additionally, although opioid analgesics are considered under essential medicines by the $\mathrm{WHO}$, access to them is severely limited in low- and middle-income countries. ${ }^{89,90}$ Use of opioid analgesics is reported to be very low in most of Africa and SoutheastAsia. With inequalities in accessibility to pain control and palliative care, the Harvard Global Equity Initiative - Lancet Commission on Global Access to Pain Control and Palliative Care (GAPCPC) aims to promote effective universal health coverage to meet palliative care needs by harnessing existing platforms for health systems strengthening. ${ }^{91}$

\section{Undertreated pain has implications for patients and caregivers}

Improvement in QoL is one of the most vital aspects and goals of cancer care, especially for end-stage cancer, ${ }^{5}$ where the focus is on symptom control and delaying disease progression. ${ }^{5}$ QoL is an important indicator of symptom relief and can be used as an assessment of the adequacy of pain management in cancer patients. ${ }^{5,92,93}$ When cancer symptoms are not optimally managed, they can have a negative impact on all aspects of a patient's QoL. ${ }^{4-694}$ Several studies conducted on cancer patients from different geographical regions and ethnicities found that pain affects physical, psychological, social, functional, and financial aspects of patients' lives. ${ }^{95-98}$ Studies conducted in Brazil, China, Taiwan, Korea, and Turkey also found that pain has detrimental effects on appetite, sleep, fatigue, daily activity, general appearance, mood, support from family, financial status, walking ability, relations with other people, enjoyment of life, nutrition, mobility, emotional status, and overall QoL of patients (Table 2). ${ }^{6,10,17,87}$

Deng et $\mathrm{al}^{6}$ reported a negative correlation between pain scores and every aspect of physical domain including appetite $(r=-0.126)$, sleep $(r=-0.069)$, fatigue $(r=-0.151)$, pain intensity ( $r=-0.871)$, daily activity $(r=-0.666)$, side effects $(r=-0.593)$, and general appearance $(r=-0.828)$. Pain scores were negatively correlated with the psychological domain; however, out of three aspects (mood, understanding of cancer, and attitudes toward treatments), the association was only statistically significant with mood $(r=-0.090)$. Within the social domain, correlation with "support from family" was negative ( $r=-0.089)$ and correlation with "support from society" was positive $(r=0.036)$. Al Qadire et $\mathrm{a}^{68}$ found that pain had the highest interference with "normal work" (mean interference score 5.8), "enjoyment of life" (mean interference score 5.7), and "sleep" (mean interference score 5.5). A significantly negative correlation of pain scores with general activities $(r=-0.649)$, sleep $(r=-0.598)$, nutrition $(r=-0.490)$, and QoL ( $r=0.671)$ was reported by Ovayolu et al. ${ }^{10}$

Several factors such as pain intensity, patient's clinical status, and absence of treatment can affect the QoL of patients with cancer pain. Patients with severe pain have reported worse QoL (mean global score 28.2) compared with patients with mild (mean global score 36.6 ) or moderate (mean global score 33.8) pain; the difference between the three groups was statistically significant. Patients with end-stage cancer who have less survival time have more pain and poorer QoL compared to patients who have more survival time. The pain score in patients with $\leq 2$ weeks survival had a mean pain score of 6.8 and a mean global QoL score of 27.9 compared to patients with $\geq 2$ weeks survival time (mean pain score 6.3 and mean global QoL score 31.4). ${ }^{6}$

Patients with an early-stage cancer had better scores on functional scales indicating better physical, role, and social functioning. On the contrary, patients who had an advancedstage cancer scored higher on the symptom scales (fatigue, pain, appetite loss, and financial difficulties). Higher score on the symptom scale represented a high level of symptomatology and problems, eventually indicating greater difficulties. Patients without pain had better scores on all of the functional scales (physical, role, emotional, cognitive, social, and global QoL). ${ }^{17}$ Patients with advanced-stage cancer also scored high on pain, swallowing, social eating, social contact, teeth, sticky saliva, pain killers, and weight loss, indicating greater impairment of function and symptoms. The scoring was representative for head and neck cancers incorporating 


\begin{tabular}{|c|c|c|c|c|c|c|}
\hline \multirow{2}{*}{ 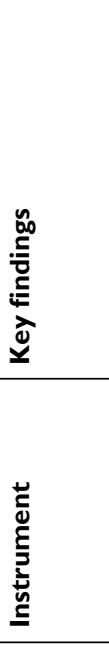 } & 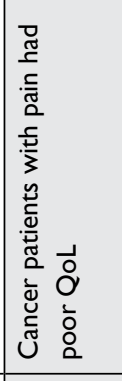 & \multicolumn{4}{|c|}{ 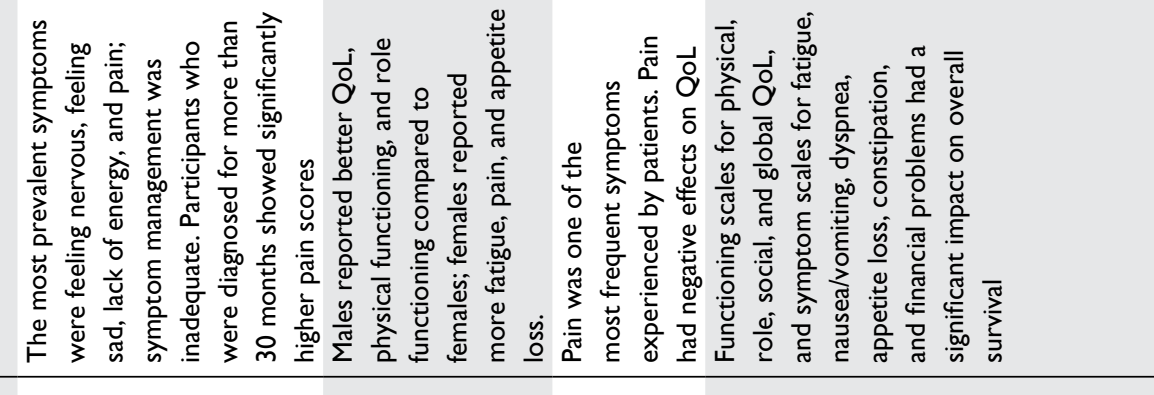 } & \multirow{2}{*}{ 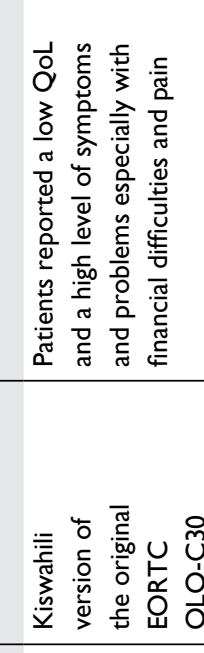 } \\
\hline & 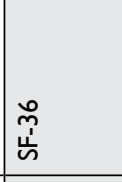 & 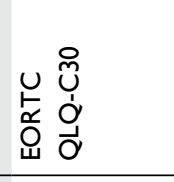 & 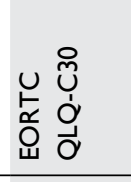 & 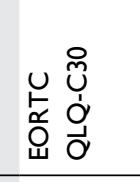 & 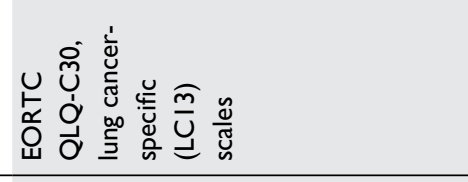 & \\
\hline 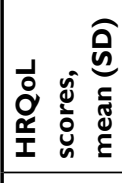 & 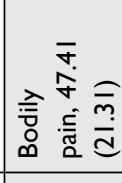 & 要 & 会䒺 & 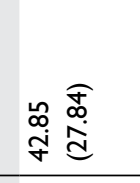 & 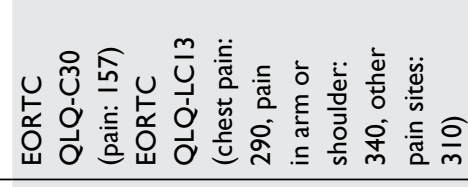 & 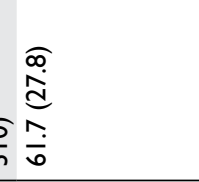 \\
\hline 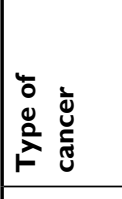 & 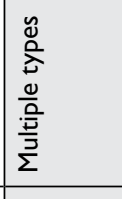 & 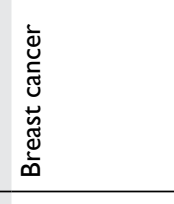 & $\begin{array}{l}\frac{\mathscr{0}}{0} \\
\frac{0}{2} \\
\frac{0}{0} \\
\frac{\overline{0}}{\bar{z}} \\
\end{array}$ & 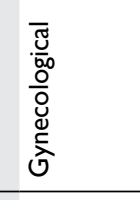 & 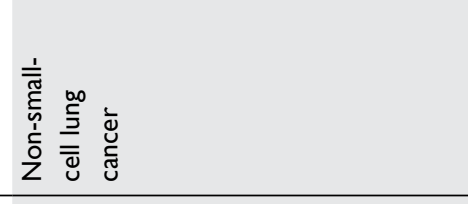 & 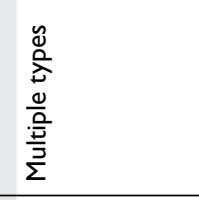 \\
\hline 童 & 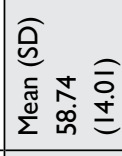 & 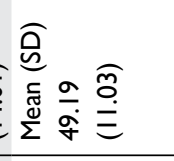 & 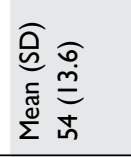 & 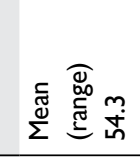 & & 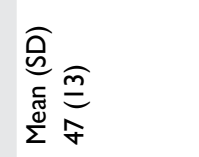 \\
\hline$z$ & \% & 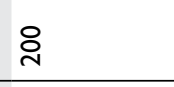 & $\stackrel{-}{8}$ & $g$ & $\stackrel{\infty}{\stackrel{\infty}{子}}$ & 흐 \\
\hline 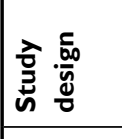 & 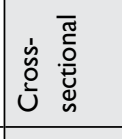 & 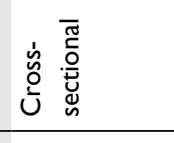 & 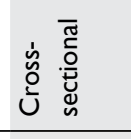 & 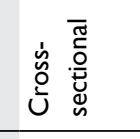 & 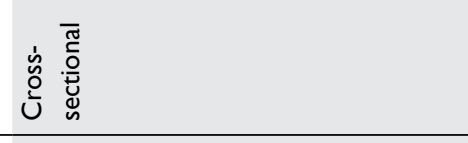 & 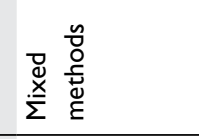 \\
\hline 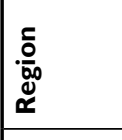 & 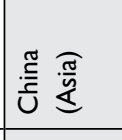 & 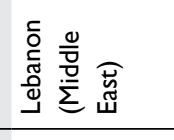 & 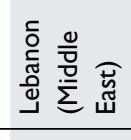 & 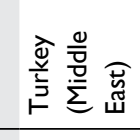 & 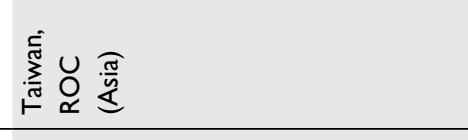 & 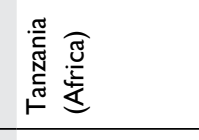 \\
\hline 辛 & 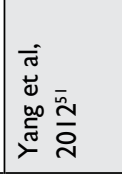 & 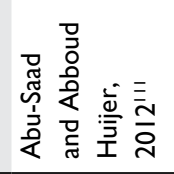 & 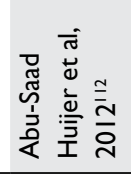 & 产商 & 苞 & 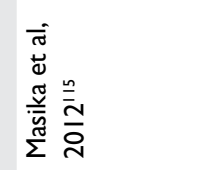 \\
\hline
\end{tabular}




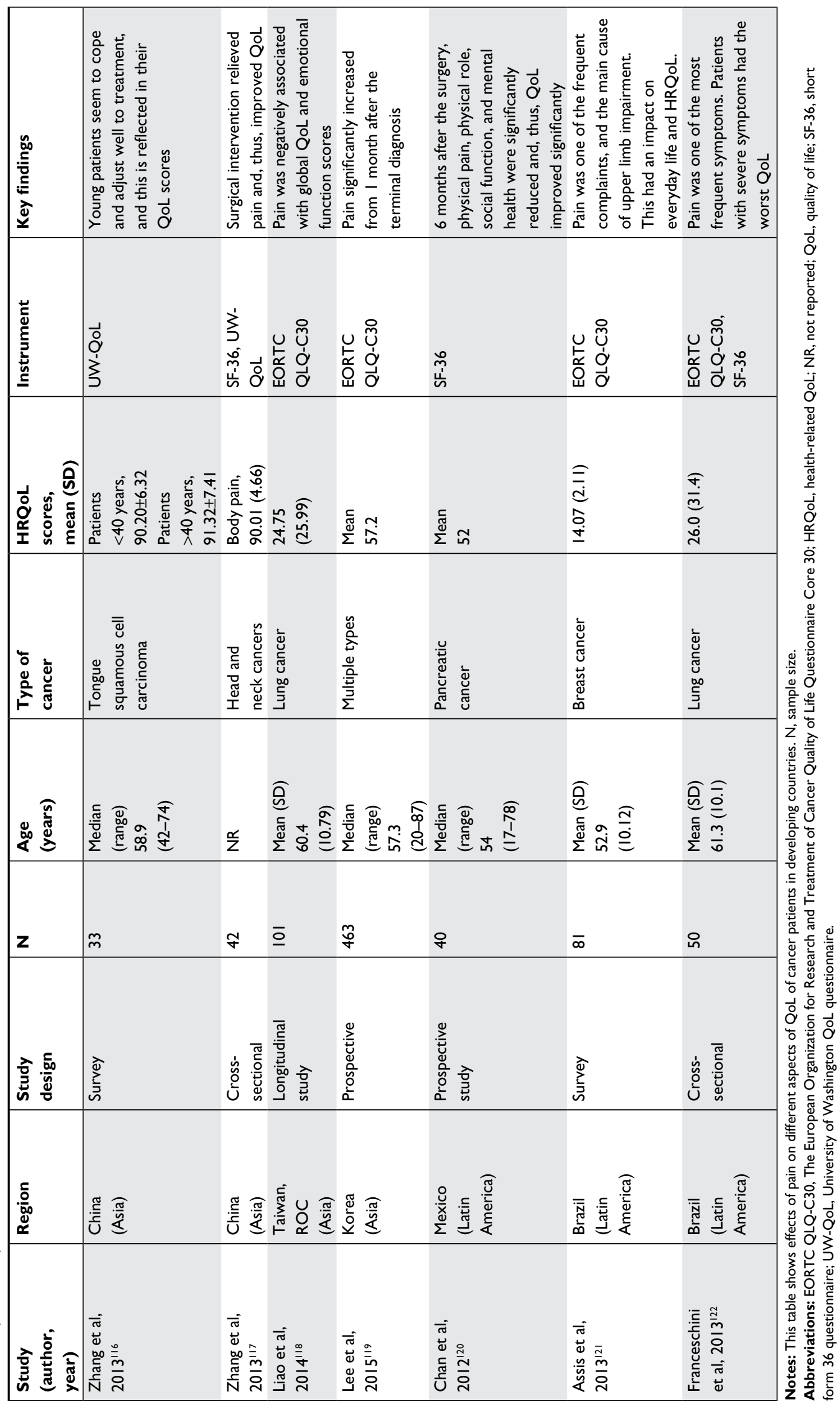


seven multi-item scales that assess pain, problems with social eating, social contact, speech, senses (taste and smell), and sexuality, which is a part of the QLQ-H\&N35 questionnaire checking symptoms and side effects of treatment, social function, and body image/sexuality. ${ }^{99}$ Compared with patients who had no pain, patients with moderate-to-severe pain showed greater impairment on the fatigue, insomnia, appetite loss, and constipation scales, while those with mild pain showed greater impairment on the nausea/vomiting and financial difficulties scales. ${ }^{17}$

It is therefore clear that inadequate pain management has a negative impact on patients. The undertreatment of pain fails to improve pain status and QoL and may even worsen the condition. It was found that patients who had received prior treatment with analgesics had more severe pain and worse QoL (mean pain score 6.6 and global QoL score 30.6) compared with analgesic naive patients (mean pain score 5.7 and global QoL score 32.4). ${ }^{6}$ Compared with radiotherapy or chemotherapy, surgical therapy showed a significant effect on social, spiritual, and general aspects of QoL. ${ }^{10}$ Pain and QoL scores were also affected by (gender) (more pain and worse QoL in women), education level (more pain and worse QoL in primary school graduates), and income (more pain and worse QoL in people with moderate income). ${ }^{10}$

Inadequate pain management also has a negative impact on caregivers. Caregivers are important stakeholders and play a critical role in pain relief strategies for patients. ${ }^{4,30}$ Caregivers are closest to patients and perform difficult, disruptive, and time-consuming tasks when providing care for patients. ${ }^{100}$ When patients have to endure cancer pain, both patients and caregivers experience deterioration in QoL. Ovayolu et $\mathrm{al}^{4}$ reported that $62.6 \%$ of caregivers experienced health problems, $56.8 \%$ of caregivers experienced fatigue, $40.9 \%$ of caregivers experienced insomnia, $27.7 \%$ of caregivers experienced loss of appetite, $10.9 \%$ of caregivers experienced diminished attention, $11.8 \%$ of caregivers experienced crying, $19.1 \%$ of caregivers experienced distress, $12.7 \%$ of caregivers experienced exhaustion, $17.7 \%$ of caregivers experienced hopelessness, $10 \%$ of caregivers experienced problems in business life, $14.1 \%$ of caregivers experienced problems in domestic life, $10.5 \%$ of caregivers experienced problems in family relationships, and $16.8 \%$ of caregivers experienced financial burden.

\section{The economic burden of cancer pain is substantial in developing countries}

Advances in cancer care have increased the survival of cancer patients, but it has also substantially increased the time that cancer patients spend in pain management. As discussed in this literature review, pain has a substantial impact on both the clinical and humanistic burden of cancer, particularly in the developing regions of the world. Three categories of costs can result from cancer pain, ie, direct costs (for medical care and for the continuing care, rehabilitation, and terminal care of patients), indirect costs (the time and productivity lost), and psychosocial costs (from reduced QoL disability, suffering, and pain, which force undesirable changes such as economic dependence, social isolation, changes or loss of job opportunities, and changed conditions of living). ${ }^{101}$

It is difficult to accurately quantify these costs especially in developing countries where there are limited research and data. It is also true that there are methodological problems and a plethora of extraneous variables that influence the reliability and validity of studies conducted in this area; however, there is no doubt that the economic burden of undertreated cancer pain is significant and presents cause for concern. There is evidence to suggest that undertreated cancer pain is linked to increased direct, indirect, and psychosocial costs. In USA, up to $76 \%$ of cancer patients experience pain that requires significant direct and indirect resource utilization. ${ }^{35}$ In terms of direct costs, global studies have shown that poorly managed/uncontrolled cancer pain results more often than not in hospitalizations, which lead to substantially increased costs of care. An analysis of unscheduled admissions at the City of Hope Medical Center (Duarte, CA, USA) estimated an annual cost for uncontrolled cancer pain that exceeded USD 5 million. ${ }^{102}$ Other direct costs associated with cancer pain management are the route of administration of analgesics, unscheduled hospitalizations, readmissions, and polypharmacy.

Indirect costs incurred while receiving care such as transportation and childcare expenses, as well as productivity losses for the patient or caregiver are less clearly documented in low- and middle-income countries. From the limited literature in the Asian population, in a recent study, $41.8 \%$ of cancer patients were estimated to be impacted with indirect cost burden from work discontinuation due to the prevalence of cancer pain. This study also showed that among those who were employed, $69.7 \%$ were estimated to be impacted with indirect cost burden from work productivity and activity impairment due to the prevalence of chronic cancer pain. ${ }^{103}$ A Swedish study reported the direct mean cost of $5998 €$ per patient and the indirect mean cost of $4460 €$ per patient annually with the diagnosis of cancer-related pain. The indirect costs on sick leave and early retirement constituted the largest 
component (59\%) followed by outpatient care and inpatient care. ${ }^{104}$ In addition, intangible costs such as pain and suffering and loss of companionship are difficult to measure but are very real to the patient and family. Another economic burden contributing significantly to cancer patients' costs and pain relief is cost of pain treatment. ${ }^{105}$

Given that most health care spending in developing countries is an out-of-pocket expense, the economic burden on patients is significant. The cost of optimal pain control for governments, however, is low especially when compared with the cost of chemotherapy and other treatments for cancer. In fact, if the direct, indirect, and psychosocial costs associated with untreated and undertreated cancer pain could be accurately calculated, the cost of optimal pain control would likely be considered a cost-effective and sound investment toward reduced future costs. Evidence from USA, UK, and Canada suggested that good palliative care for cancer could lower health care costs of patients who are dying as well as reduce costs by reducing the frequency of hospitalization. ${ }^{106}$ Also, although developing countries have shown good palliative care for cancer, there is a need to be wary of the potential humanistic burden of abuse and misuse of opioids since countries such as USA face grave challenges such as opioid abuse for chronic noncancer pain, wherein the health and economic burden of opioid abuse on individuals, their families, and society is substantial. ${ }^{107}$

Data from the International Agency for Research on Cancer show that more than half of all cancer cases $(57 \%)$ and cancer deaths $(65 \%)$ in 2012 occurred in low-income regions ${ }^{83,84}$ In these regions, the disease is mostly discovered when it is at an advanced stage because of a low capacity to prevent and detect cancer early. ${ }^{85}$ In an African study, up to $76 \%$ of cancer patients experienced pain that required significant direct and indirect resource utilizations. ${ }^{108}$ Since lower levels of income were found to be a significant predictor of high direct cost,${ }^{35}$ it can be inferred that there is a probable higher economic burden of cancer pain in low- and middleincome countries. Increasing urbanization, widespread tobacco consumption, scarcity of resources, and inadequacy of efficient care may further exacerbate the burden of cancer pain in developing countries.

\section{Conclusion}

An increased focus on NCDs by the WHO has led to a growing awareness on the burden of cancer. The global incidence of cancer is projected to rise from 14 million in 2012 to 22 million over the next two decades. Approximately half of the new cases are expected to occur in Asia by $2030 .{ }^{86}$ Although cancer affects all countries, there is a disproportionate burden of cancer incidence and prevalence in developing countries. This burden is amplified by an associated burden of untreated and undertreated cancer pain.

Due to various barriers, pain is poorly reported, diagnosed, understood, and managed. In resource-constrained settings, where cancer management itself is not adequate, pain management is not considered a priority. Under managed pain has a debilitating effect on almost every aspect of a patient's life - physical, psychological, and social. Daily activity, ability to work, quality of sleep, appetite, social interaction, and family relations are impacted. The high economic burden of pain leaves families in distress and makes patients feel guilt and a burden to their families, which eventually leads to pain undertreatment.

There is a pressing need to raise awareness of the prevalence of cancer pain, its debilitating effects, and standards of care. Patients, caregivers, and clinicians should be appropriately educated regarding the use and recognition of analgesics, while governments should ensure that effective medication is both available and accessible. Also, evidence from USA, UK, and Canada suggested that good palliative care for cancer could lower health care costs of patients who are dying as well as reduce costs by reducing the frequency of hospitalization. ${ }^{106}$

Thus, optimal treatment of cancer pain should be highlighted as a priority in developing countries and concerted efforts should be made to eliminate the barriers for effective care and treatment. In order to expand access to pain treatment, it is necessary to transform the way in which pain is approached, understood, assessed, recognized by health authorities, and treated. There are numerous gaps in policy, treatment, attitudes, and education that need to be addressed. Furthermore, there is a need to conduct more research in this field to generate empirical, reliable, and robust data to support an evidence-based approach to addressing the management of cancer pain and its impact in developing countries.

Despite WHO recommendations for pain relief (1986), $59 \%$ of cancer patients suffer from cancer-related pain during active therapy phase and $65 \%$ of cancer patients suffer during advanced disease. An estimated 6.6 million patients die of cancer every year, and WHO estimated 9 million new cancer cases, with more than half from developing countries. Thus, unrelieved cancer pain still remains a major issue and an increase in its prevalence in low- and 
middle-income countries such as cancer itself is of global concern. ${ }^{109}$ Interestingly, a cross-sectional study identified that in countries with limited resources for subsidy and reimbursement for opioid analgesics, additional costs from regulatory requirements might be transferred directly onto patients, identifying another economic burden on patients, which needs to be addressed. ${ }^{110}$ It is therefore important that governments in developing countries facilitate positive changes at national and regional levels, improving both access to pain-related medicines and including pain treatment in the reimbursement coverage, same as cancer therapies for cancer patients.

\section{Abbreviations}

CAMs, complementary and alternative medicines; CEA, cost effective analysis; GAPCPC, Global Access to Pain Control and Palliative Care; HRQoL, health-related quality of life; INCB, International Narcotics Control Board; NCDs, noncommunicable disease; NHS EED, NHS Economic Evaluation Database; NSAIDs, nonsteroidal anti-inflammatory drugs; NSSO, National Sample Survey Organization; QoL, quality of life; TCM, Traditional Chinese Medicine.

\section{Acknowledgments}

We thank Dr Shikha Singh from Kantar Health for assistance in the revision of the manuscript. This study was funded by Mundipharma Pte Ltd. Kantar Health received funding from Mundipharma Pte Ltd for the conduct of the study and the development of manuscript. The experts' kick-off meeting for this manuscript and initiative was during 17th World Congress of Pain in Yokohama, Japan. The abstract, methodology, and preliminary results of this article were presented at the XII Conference of International Association of Study of Pain - African Chapter SAETD as a conference talk.

\section{Author contributions}

Zhang Li, Tiara Aninditha, Brahim Griene, Javier Francis, Paulo Renato, Alain Serrie, and Indira Umareddy performed the literature searches, reviewed the retrieved articles and reports, and also created the first draft of the manuscript. Sebastien Boisseau and Yacine Hadjiat provided substantive comments on the methodology and edits to the manuscript. All authors contributed toward data analysis, drafting and revising the paper, gave final approval of the version to be published, and agree to be accountable for all aspects of the work.

\section{Disclosure}

Sebastien Boisseau and Yacine Hadjiat are employees of Mundipharma Pte Ltd. Indira Umareddy is an employee of Kantar Health. The authors report no other conflicts of interest in this work.

\section{References}

1. Islam SMS, Purnat TD, Phuong NTA, Mwingira U, Schacht K, Fröschl G. Non-Communicable Diseases (NCDs) in developing countries: a symposium report. Global Health. 2014;10:81.

2. Mishra A, Meherotra R. Head and neck cancer: global burden and regional trends in India. Asian Pac J Cancer Prev. 2014;15(2):537-550.

3. Fact Sheets by Population [webpage on the Internet]. Population Fact Sheets. Available from: http://globocan.iarc.fr/Pages/fact_sheets_population.aspx. Accessed August 3, 2017.

4. Ovayolu Ö, Ovayolu N, Aytaç S, Serçe S, Sevinc A. Pain in cancer patients: pain assessment by patients and family caregivers and problems experienced by caregivers. Support Care Cancer. 2015;23(7):1857-1864.

5. Liang SY, Ding SA, Wu WW, Liu CY, Lin CC. Opioid-taking selfefficacy affects the quality of life of Taiwanese patients with cancer pain. Support Care Cancer. 2015;23(7):2113-2120.

6. Deng D, Fu L, Zhao YX, et al. The relationship between cancer pain and quality of life in patients newly admitted to Wuhan Hospice Center of China. Am J Hosp Palliat Care. 2012;29(1):53-59.

7. He QH, Liu QL, Li Z, Li KZ, Xie YG. Impact of epidural analgesia on quality of life and pain in advanced cancer patients. Pain Manag Nurs. 2015;16(3):307-313.

8. Hong SH, Roh SY, Kim SY, et al. Change in cancer pain management in Korea between 2001 and 2006: results of two nationwide surveys. J Pain Symptom Manage. 2011;41(1):93-103.

9. van den Beuken-van Everdingen MH, de Rijke JM, Kessels AG, Schouten HC, van Kleef M, Patijn J. High prevalence of pain in patients with cancer in a large population-based study in The Netherlands. Pain. 2007;132(3):312-320

10. Ovayolu N, Ovayolu Ö, Serçe S, Tuna D, Pirbudak Çöçelli L, Sevinç A. Pain and quality of life in Turkish cancer patients. Nurs Health Sci. 2013;15(4):437-443.

11. Breivik H, Cherny N, Collett B, et al. Cancer-related pain: a panEuropean survey of prevalence, treatment, and patient attitudes. Ann Oncol. 2009;20(8):1420-1433.

12. WHO [webpage on the Internet]. WHO's cancer pain ladder for adults. Available from: http://www.who.int/cancer/palliative/painladder/en/. Accessed May 2, 2017.

13. Zech DFJ, Grond S, Lynch J, Hertel D, Lehmann KA. Validation of World Health Organization Guidelines for cancer pain relief: a 10-year prospective study. Pain. 1995;63(1):65-76.

14. Javier FO, Irawan C, Mansor MB, Sriraj W, Tan KH, Thinh DHQ. Cancer Pain Management Insights and Reality in Southeast Asia: Expert Perspectives From Six Countries. J Glob Oncol. 2016;2(4):235-243.

15. Kim YS, Do H, Lee JW, et al. Patient reporting pain intensity immediately after surgery can be associated with underlying depression in women with breast cancer. Psychooncology. 2016;25(3):308-315.

16. Ovayolu N, Ovayolu Ö, Serçe S, Tuna D, Pirbudak Çöçelli L, Sevinç A. Pain and quality of life in Turkish cancer patients. Nurs Health Sci. 2013;15(4):437-443.

17. Oliveira KG, von Zeidler SV, Podestá JR, et al. Influence of pain severity on the quality of life in patients with head and neck cancer before antineoplastic therapy. BMC Cancer. 2014;14(1):39.

18. Alkan A, Guc ZG, Senler FC, et al. Breast cancer survivors suffer from persistent postmastectomy pain syndrome and posttraumatic stress disorder (ORTHUS study): a study of the palliative care working committee of the Turkish Oncology Group (TOG). Support Care Cancer. 2016;24(9):3747-3755. 
19. Ahmed A, Bhatnagar S, Rana SP, Ahmad SM, Joshi S, Mishra S. Prevalence of phantom breast pain and sensation among postmastectomy patients suffering from breast cancer: a prospective study. Pain Pract. 2014;14(2):E17-E28.

20. Rau KM, Chen JS, Wu HB, et al. The impact of pain control on physical and psychiatric functions of cancer patients: a nation-wide survey in Taiwan. Jpn J Clin Oncol. 2015;45(11):1042-1049.

21. O’Mahony S, Goulet J, Kornblith A, et al. Desire for hastened death, cancer pain and depression: report of a longitudinal observational study. J Pain Symptom Manage. 2005;29(5):446-457.

22. WHO. National Cancer Control Programmes. Available from: http:// www.who.int/cancer/media/en/408.pdf. Accessed July 21, 2017.

23. Fairchild A. Under-treatment of cancer pain. Curr Opin Support Palliat Care. 2010;4(1):11-15.

24. Deandrea S, Montanari M, Moja L, Apolone G. Prevalence of undertreatment in cancer pain. A review of published literature. Ann Oncol. 2008;19(12):1985-1991.

25. Cleary J, Radbruch L, Torode J, Cherny NI. Formulary availability and regulatory barriers to accessibility of opioids for cancer pain in Asia: a report from the Global Opioid Policy Initiative (GOPI). Ann Oncol. 2013;24(Suppl 11):xi24-xi32.

26. Lynch T, Connor S, Clark D. Mapping levels of palliative care development: a global update. J Pain Symptom Manage. 2013;45(6): 1094-1106.

27. Seya MJ, Gelders SF, Achara OU, Milani B, Scholten WK. A first comparison between the consumption of and the need for opioid analgesics at country, regional, and global levels. J Pain Palliat Care Pharmacother. 2011;25(1):6-18.

28. Foley KM, Wagner JL, Joranson DE, Gelband H [database on the Internet]. Pain Control for People with Cancer and AIDS. In: Jamison DT, Breman JG, Measham AR, editors. Disease Control Priorities in Developing Countries [Internet]. 2nd ed. Washington, DC: World Bank; 2006 [cited February 20, 2017]. Available from: http://www. ncbi.nlm.nih.gov/books/NBK11800/. Accessed October 9, 2018

29. Lebaron V, Beck SL, Maurer M, Black F, Palat G. An ethnographic study of barriers to cancer pain management and opioid availability in India. Oncologist. 2014;19(5):515-522.

30. Li YX, Yu JQ, Tang L, et al. Cancer pain management at home: voice from an underdeveloped region of China. Cancer Nurs. 2013;36(4):326-334.

31. Al Qadire M, Tubaishat A, Aljezawi MM. Cancer pain in Jordan: prevalence and adequacy of treatment. Int J Palliat Nurs. 2013;19(3):125-130.

32. Harrington CB, Hansen JA, Moskowitz M, Todd BL, Feuerstein M. It's not over when it's over: long-term symptoms in cancer survivors--a systematic review. Int J Psychiatry Med. 2010;40(2):163-181.

33. Mayer DK, Travers D, Wyss A, Leak A, Waller A. Why do patients with cancer visit emergency departments? Results of a 2008 population study in North Carolina. J Clin Oncol. 2011;29(19):2683-2688.

34. Foley KM. The relationship of pain and symptom management to patient requests for physician-assisted suicide. J Pain Symptom Manage. 1991;6(5):289-297.

35. Fortner BV, Demarco G, Irving G, et al. Description and predictors of direct and indirect costs of pain reported by cancer patients. J Pain Symptom Manage. 2003;25(1):9-18.

36. Global status report on noncommunicable diseases 2014 [Internet]. [cited April 11, 2017]. Available from: https://www.who.int/nmh/ publications/ncd-status-report-2014/en/. Accessed October 19, 2018.

37. WHO. Global action plan for the prevention and control of noncommunicable diseases 2013-2020. [cited April 11, 2017]. Available from: http://apps.who.int/iris/bitstream/10665/94384/1/9789241506236_ eng.pdf. Accessed April 11, 2017.

38. International Agency for Research on Cancer. Biennial Report. Available from: http://governance.iarc.fr/SC/SC52/SC52_2.pdf. Accessed September 11, 2018.
39. Yabroff KR, Lund J, Kepka D, Mariotto A. Economic burden of cancer in the United States: estimates, projections, and future research. Cancer Epidemiol Biomarkers Prev. 2011;20(10):2006-2014.

40. Guy GP, Berkowitz Z, Ekwueme DU, Rim SH, Yabroff KR. Annual Economic Burden of Productivity Losses Among Adult Survivors of Childhood Cancers. Pediatrics. 2016;138(Suppl 1):S15-S21.

41. Zhang X, Liu S, Liu Y, et al. Economic Burden for Lung Cancer Survivors in Urban China. Int J Environ Res Public Health. 2017;14(3):E308.

42. Lee KS, Chang HS, Lee SM, Park EC. Economic Burden of Cancer in Korea during 2000-2010. Cancer Res Treat. 2015;47(3): 387-398.

43. Mahal A, Karan A, Fan VY, Engelgau M. The economic burden of cancers on Indian households. PLoS One. 2013;8(8):e71853.

44. Marventano S, Forjaz M, Grosso G. et al. Health related quality of life in colorectal cancer patients: state of the art. BMC Surg. 2013;13(Suppl 2):S15.

45. Heydarnejad MS, Hassanpour DA, Solati DK. Factors affecting quality of life in cancer patients undergoing chemotherapy. Afr Health Sci. 2011;11(2):266-270.

46. Reeve BB, Potosky AL, Smith AW, et al. Impact of cancer on health-related quality of life of older Americans. J Natl Cancer Inst. 2009;101(12): 860-868.

47. Lim HA, Tan JY, Chua J, et al. Quality of life of family caregivers of cancer patients in Singapore and globally. Singapore Med J. 2017;58(5):258-261.

48. Yusuf AJ, Adamu A, Nuhu FT. Caregiver burden among poor caregivers of patients with cancer in an urban African setting. Psychooncology. 2011;20(8):902-905.

49. van den Beuken-van Everdingen MH, de Rijke JM, Kessels AG, Schouten HC, van Kleef M, Patijn J. High prevalence of pain in patients with cancer in a large population-based study in The Netherlands. Pain. 2007;132(3):312-320.

50. van den Beuken-van Everdingen MH, Hochstenbach LM, Joosten EA Tjan-Heijnen VC, Janssen DJ. Update on prevalence of pain in patients with cancer: systematic review and meta-analysis. J Pain Symptom Manage. 2016;51(6):1070-1090.

51. Yang P, Sun L-Q, Lu Q, Pang D, Ding Y. Quality of life in cancer patients with pain in Beijing. Chin J Cancer Res Chung-Kuo Yen Cheng Yen Chiu. 2012;24(1):60-66.

52. Kim JY, Jang WY, Hur MH, et al. Prevalence and management of pain by different age groups of Korean cancer patients. Am J Hosp Palliat Care. 2013;30(4):393-398.

53. Halawi R, Aldin ES, Baydoun A, et al. Physical symptom profile for adult cancer inpatients at a Lebanese cancer unit. Eur J Intern Med. 2012;23(8):e185-e189.

54. Hamid GA, Saeed NM, Ba-Ashen Y, Ba-Kubirah R. Colorectal carcinoma at Al-Gamhouria Teaching Hospital, Aden, Yemen. Gulf J Oncolog. 2012;11(11):16-19.

55. Beck SL, Falkson G. Prevalence and management of cancer pain in South Africa. Pain. 2001;94(1):75-84.

56. Harding R, Selman L, Agupio G, et al. The prevalence and burden of symptoms amongst cancer patients attending palliative care in two African countries. Eur J Cancer. 2011;47(1):51-56.

57. Nogueira RTE, Érica Brandão de Moraes V, Sousa LHA, Garcia JBS, Vieira Éb de M. Difficult situation in cancer pain: breakthrough pain. Revista Dor. 2014;15(1):41-47.

58. Pracucho EM, Lopes LR, Zanatto RM, et al. Profile of patients with gastrointestinal stromal tumors (GIST). Arq Bras Cir Dig. 2015;28(2):124-127

59. Saini S, Bhatnagar S. Cancer pain management in developing countries. Indian J Palliat Care. 2016;22(4):373.

60. Corli O, Martoni AA, Porcu L, et al. Non-clinical factors influencing pain intensity in cancer patients: Socio-cultural-economic status, awareness of disease and the relation with the oncologist. Eur J Intern Med. 2016;33:e18-e19. 
61. Vallerand AH, Templin T, Hasenau SM, Riley-Doucet C. Factors that affect functional status in patients with cancer-related pain. Pain. 2007;132(1-2):82-90.

62. Soltow D, Given BA, Given CW. Relationship between age and symptoms of pain and fatigue in adults undergoing treatment for cancer. Cancer Nurs. 2010;33(4):296-303.

63. Valeberg BT, Miaskowski C, Hanestad BR, Bjordal K, Paul S, Rustøen T. Demographic, clinical, and pain characteristics are associated with average pain severity groups in a sample of oncology outpatients. $J$ Pain. 2008;9(10):873-882.

64. Gärtner R, Jensen MB, Nielsen J, Ewertz M, Kroman N, Kehlet H. Prevalence of and factors associated with persistent pain following breast cancer surgery. JAMA. 2009;302(18):1985-1992.

65. Koshy RC, Rhodes D, Devi S, Grossman SA. Cancer pain management in developing countries: a mosaic of complex issues resulting in inadequate analgesia. Support Care Cancer. 1998;6(5):430-437.

66. Pacific Cancer Program. Pain reliveing drugs in 12 African pepfar countries. Available from: http://www.pacificcancer.org/pacpresources/palliative-care-cancer-survivorship/pain-relieving-drugs12-african-pepfar-countries.pdf. Accessed September 11, 2018.

67. WHO [webepage on the Internet]. Controlled substances [Internet]. WHO. Available from: http://www.who.int/medicines/access/ controlled-substances/en/. Accessed October 9, 2018.

68. Al Qadire M, Tubaishat A, Aljezawi MM. Cancer pain in Jordan: prevalence and adequacy of treatment. Int $J$ Palliat Nurs. 2013;19(3):125-130.

69. Amoatey Odonkor C, Addison W, Smith S, Osei-Bonsu E, Tang T, Erdek M. Connecting the dots: a comparative global multi-institutional study of prohibitive factors affecting cancer pain management. Pain Med. 2017;18(2):363-373.

70. Javier FO, Calimag MP. Opioid Use in the Philippines - 20 years after the introduction of the WHO analgesic ladder. Eur J Pain Suppl. 2007;1(S1):19-22.

71. Messac L. The other opioid crisis - people in poor countries can't get the pain medication they need [Internet]. The Conversation. Available from: http://theconversation.com/the-other-opioid-crisis-peoplein-poor-countries-cant-get-the-pain-medication-they-need-56205. Accessed March 25, 2016.

72. Charalambous H, Protopapa E, Gavrielidou D, Avgousti V. Physicians' prescribing habits for cancer pain in Cyprus. Ann Oncol. 2012;23(Suppl 3):79-83.

73. Guru-Murthy K [webpage on the Internet]. The African cancer patients dying in unnecessary pain | Krishnan Guru-Murthy. The Guardian; 2014. Available from: https:/www.theguardian.com/world/2014/ may/29/african-cancer-patients-dying-unnecessary-pain. Accessed October 9, 2018 .

74. Xia Z. Cancer pain management in China: current status and practice implications based on the ACHEON survey. J Pain Res. 2017;10:1943-1952.

75. Oyunchimeg B, Hwang JH, Ahmed M, Choi S, Han D. Complementary and alternative medicine use among patients with cancer in Mongolia: a National hospital survey. BMC Complement Altern Med. 2017;17(1):58.

76. Carr EC, Meredith P, Chumbley G, Killen R, Prytherch DR, Smith GB. Pain: a quality of care issue during patients' admission to hospital. $J$ Adv Nurs. 2014;70(6):1391-1403.

77. Wang W-Y, Ho S-T, Wu S-L, et al. Trends in Clinically Significant Pain Prevalence Among Hospitalized Cancer Patients at an Academic Hospital in Taiwan. Medicine (Baltimore). 2016;95(1):e2099.

78. Lim SN, Han HS, Lee KH, et al. A satisfaction survey on cancer pain management using a self-reporting pain assessment tool. J Palliat Med. 2015;18(3):225-231.

79. Human Rights Watch - Global State of Pain Treatment. Access to Palliative Care as a Human Right. [cited February 20, 2017]. Available from: https://www.hrw.org/sites/default/files/reports/hhr0511W.pdf.
80. Gelband H, Jha P, Sankaranarayanan R, Horton S, editors [database on the Internet]. Cancer: Disease Control Priorities, Third Edition (Volume 3). Washington, DC: The International Bank for Reconstruction and Development/The World Bank; 2015 [cited February 20, 2017]. Available from: http:/www.ncbi.nlm.nih.gov/books/NBK343628/. Accessed November 1, 2015.

81. WHO. Access to Controlled Medications Programme. Available from: http://www.who.int/medicines/areas/quality_safety/AccessControlledMedicinesProgr.Framework.pdf. Accessed September 10, 2018.

82. Human Rights Watch. Access to Palliative care as human right. Available from: https://www.hrw.org/sites/default/files/reports/hhr0511W. pdf. Accessed September 10, 2018.

83. Li YX, Yu JQ, Tang L, et al. Cancer pain management at home: voice from an underdeveloped region of China. Cancer Nurs. 2013;36(4): 326-334.

84. Bakshi SG, Jain P, Kannan S. An assessment of basic pain knowledge and impact of pain education on Indian Anaesthesiologists - a pre and post questionnaire study. Indian J Anaesth. 2014;58(2):127-131.

85. Briggs EV, Battelli D, Gordon D, et al. Current pain education within undergraduate medical studies across Europe: Advancing the Provision of Pain Education and Learning (APPEAL) study. BMJ Open. 2015;5(8):e006984.

86. Buchman DZ, Ho A, Illes J. You present like a drug addict: patient and clinician perspectives on trust and trustworthiness in chronic pain management. Pain Med. 2016;17(8):1394-1406.

87. Kwon JH, Oh SY, Chisholm G, et al. Predictors of high score patientreported barriers to controlling cancer pain: a preliminary report. Support Care Cancer. 2013;21(4):1175-1183.

88. Lee GL, Pang GS, Akhileswaran R, et al. Understanding domains of health-related quality of life concerns of Singapore Chinese patients with advanced cancer: a qualitative analysis. Support Care Cancer. 2016;24(3):1107-1118.

89. WHO, WHO Expert Committee on the Selection, and Use of Essential Medicines, World Health Organization. WHO model list of essential medicines: 16th list (updated) March 2010; 2010 [cited July 24, 2017]; Available from: http://apps.who.int/iris/bitstream/10665/70643/1/ a95060_eng.pdf. Accessed July 27, 2017.

90. Berterame S, Erthal J, Thomas J, et al. Use of and barriers to access to opioid analgesics: a worldwide, regional, and national study. Lancet. 2016;387(10028):1644-1656.

91. Health in the Americas [webpage on the Internet] The quest for universal health: summary of indicators on health systems performance 2017. Available from: https:/www.paho.org/salud-en-las-americas2017/?p=65. Accessed October 09, 2018.

92. Cella DF, Tulsky DS, Gray G, et al. The Functional Assessment of Cancer Therapy scale: development and validation of the general measure. J Clin Oncol. 1993;11(3):570-579.

93. Mcmillan SC, Weitzner M. Quality of life in cancer patients: use of a revised Hospice Index. Cancer Pract. 1998;6(5):282-288.

94. Yamagishi A, Morita T, Miyashita M, et al. Pain intensity, quality of life, quality of palliative care, and satisfaction in outpatients with metastatic or recurrent cancer: a Japanese, nationwide, region-based, multicenter survey. J Pain Symptom Manage. 2012;43(3):503-514.

95. Potter J, Higginson IJ. Pain experienced by lung cancer patients: a review of prevalence, causes and pathophysiology. Lung Cancer. 2004;43(3):247-257.

96. Goudas LC, Bloch R, Gialeli-Goudas M, Lau J, Carr DB. The epidemiology of cancer pain. Cancer Invest. 2005;23(2):182-190.

97. Yun YH, Heo DS, Lee IG, et al. Multicenter study of pain and its management in patients with advanced cancer in Korea. J Pain Symptom Manage. 2003;25(5):430-437.

98. Miaskowski C, Zimmer EF, Barrett KM, Dibble SL, Wallhagen M. Differences in patients' and family caregivers' perceptions of the pain experience influence patient and caregiver outcomes. Pain. 1997;72(1-2):217-226. 
99. EORTC QLQ-C30 Scoring Manual [Internet]. [cited December 13, 2017]. Available from: https:/www.eortc.be/qol/files/SCManualQLQC30.pdf. Accessed October 19, 2018.

100. Stenberg U, Ruland CM, Miaskowski C. Review of the literature on the effects of caring for a patient with cancer. Psychooncology. 2010;19(10):1013-1025.

101. Gusterson B. Cancer Prevention and Control. In: Greenwald P, Kramer BS, Wee DL, editors. New York: Marcel Dekker; 1994.

102. Ferrell BR, Griffith H, Wmdr K. Special section on the Economics of pain management. Cost issues related to pain management: report from the cancer pain panel of the agency for health care policy and research. Available from: https://www.jpsmjournal.com/ article/0885-3924(94)90098-1/pdf. Accessed October 19, 2018.

103. ACHEON Working Group, Kim YC, Ahn JS, et al. Current practices in cancer pain management in Asia: a survey of patients and physicians across 10 countries. Cancer Med. 2015;4(8):1196-1204.

104. Gustavsson A, Bjorkman J, Ljungcrantz C. Socio-economic burden of patients with a diagnosis related to chronic pain - Register data of 840,000 Swedish patients: Socio-economic burden of patients with a diagnosis related to chronic pain. Eur J Pain. 2012;16(2):289-299.

105. Foley KM, Wagner JL, Joranson DE, Gelband H [database on the Internet]. Pain control for people with cancer and AIDS. In: Jamison DT, Breman JG, Measham AR, et al. editors. Disease Control Priorities in Developing Countries [Internet]. 2nd ed. Washington, DC: World Bank; 2006 [cited July 25, 2017]. Available from: http://www.ncbi. nlm.nih.gov/books/NBK11800/. Accessed October 16, 2018.

106. TWF. Cost-effectiveness of Palliative Care. Available from: http:// hpcintegration.ca/media/24434/TWF-Economics-report-Final.pdf. Accessed July 25, 2017.

107. Florence CS, Zhou C, Luo F, Xu L. The Economic Burden of Prescription Opioid Overdose, Abuse, and Dependence in the United States, 2013. Med Care. 2016;54(10):901-906.

108. Harding R, Selman L, Agupio G, et al. The prevalence and burden of symptoms amongst cancer patients attending palliative care in two African countries. Eur J Cancer. 2011;47(1):51-56.

109. van den Beuken-van Everdingen MH, de Rijke JM, Kessels AG, Schouten $\mathrm{HC}$, van Kleef M, Patijn J. Prevalence of pain in patients with cancer: a systematic review of the past 40 years. Ann Oncol. 2007;18(9):1437-1449.

110. Supplement-AR15_availability_English.pdf [Internet]. [cited July 25, 2017]. Available from: https://www.incb.org/documents/Publications/AnnualReports/AR2015/English/Supplement-AR15_availability_English.pdf. Accessed October 19, 2018.
111. Abu-Saad Huijer H, Abboud S. Health-related quality of life among breast cancer patients in Lebanon. Eur J Oncol Nurs. 2012;16(5):491-497.

112. Abu-Saad Huijer H, Abboud S, Doumit M. Symptom prevalence and management of cancer patients in Lebanon. J Pain Symptom Manage. 2012;44(3):386-399.

113. Akkuzu G. Quality of life of women undergoing chemotherapy for a gynaecological oncological disease in Turkey. Asian Pac J Cancer Prev. 2012;13(4):1277-1280.

114. Li TC, Li CI, Tseng CH, et al. Quality of life predicts survival in patients with non-small cell lung cancer. BMC Public Health. 2012;12:790.

115. Masika GM, Wettergren L, Kohi TW, von Essen L. Health-related quality of life and needs of care and support of adult Tanzanians with cancer: a mixed-methods study. Health Qual Life Outcomes. 2012;10(1):133.

116. Zhang X, Fang QG, Li ZN, Li WL, Liu FY, Sun CF. Quality of life in patients younger than 40 years treated for anterior tongue squamous cell carcinoma. J Craniofac Surg. 2013;24(6):e558-e561.

117. Zhang X, Li MJ, Fang QG, Li ZN, Li WL, Sun CF. Free fibula flap: assessment of quality of life of patients with head and neck cancer who have had defects reconstructed. J Craniofac Surg. 2013;24(6):2010-2013.

118. Liao YC, Shun SC, Liao WY, Yu CJ, Yang PC, Lai YH. Quality of life and related factors in patients with newly diagnosed advanced lung cancer: a longitudinal study. Oncol Nurs Forum. 2014;41(2): E44-E55.

119. Lee MK, Lee WJ, do YR, et al. Changes in health-related quality of life and quality of care among terminally ill cancer patients and survival prediction: Multicenter prospective cohort study. Palliat Support Care. 2015;13(4):1103-1111.

120. Chan C, Franssen B, Domínguez I, Ramírez-del Val A, Uscanga LF, Campuzano M. Impact on quality of life after pancreatoduodenectomy: a prospective study comparing preoperative and postoperative scores. J Gastrointest Surg. 2012;16(7):1341-1346.

121. Assis MR, Marx AG, Magna LA, Ferrigno IS. Late morbidity in upper limb function and quality of life in women after breast cancer surgery. Braz J Phys Ther. 2013;17(3):236-243.

122. Franceschini J, Jardim JR, Fernandes ALG, Jamnik S, Santoro IL. Relationship between the magnitude of symptoms and the quality of life: a cluster analysis of lung cancer patients in Brazil. J Bras Pneumol. 2013;39(1):23-31.
ClinicoEconomics and Outcomes Research

\section{Publish your work in this journal}

ClinicoEconomics and Outcomes Research is an international, peerreviewed open-access journal focusing on health technology assessment, pharmacoeconomics and outcomes research in the areas of diagnosis, medical devices, and clinical, surgical and pharmacological intervention. The economic impact of health policy and health systems
Dovepress

organization also constitute important areas of coverage. The manuscript management system is completely online and includes a very quick and fair peer-review system, which is all easy to use. Visit http://www.dovepress.com/testimonials.php to read real quotes from published authors. 